\title{
Correction to: Mechanical Ventilation in Neonates and Children
}

\author{
Ashok P. Sarnaik, Shekhar T. Venkataraman, and Bradley A. Kuch
}

\section{Correction to:}

\section{A. P. Sarnaik et al. (eds.), Mechanical Ventilation in Neonates and Children, https://doi.org/10.1007/978-3-030-83738-9}

The original version of the book was published with images where the labels and text were misaligned and were inadvertently processed as such for the chapters 1, 2, 3 and 7. The erratum chapter has been updated with the changes.

\footnotetext{
The updated versions of these chapters can be found at https://doi.org/10.1007/978-3-030-83738-9_1 https://doi.org/10.1007/978-3-030-83738-9_2 https://doi.org/10.1007/978-3-030-83738-9_3 https://doi.org/10.1007/978-3-030-83738-9_7 